\title{
Fabrication of a novel catalyst reactor with improved strength and catalytic performance used for automotive exhaust treatment
}

DOI:

10.1021/acs.iecr.8b05641

\section{Document Version}

Accepted author manuscript

Link to publication record in Manchester Research Explorer

Citation for published version (APA):

Cai, H., Guo, F., Zhang, X., Wang, X., Hu, L., Zhao, X., \& Xiao, P. (2019). Fabrication of a novel catalyst reactor with improved strength and catalytic performance used for automotive exhaust treatment. Industrial \& Engineering Chemistry Research. https://doi.org/10.1021/acs.iecr.8b05641

Published in:

Industrial \& Engineering Chemistry Research

\section{Citing this paper}

Please note that where the full-text provided on Manchester Research Explorer is the Author Accepted Manuscript or Proof version this may differ from the final Published version. If citing, it is advised that you check and use the publisher's definitive version.

\section{General rights}

Copyright and moral rights for the publications made accessible in the Research Explorer are retained by the authors and/or other copyright owners and it is a condition of accessing publications that users recognise and abide by the legal requirements associated with these rights.

\section{Takedown policy}

If you believe that this document breaches copyright please refer to the University of Manchester's Takedown Procedures [http://man.ac.uk/04Y6Bo] or contact uml.scholarlycommunications@manchester.ac.uk providing relevant details, so we can investigate your claim.

\section{OPEN ACCESS}




\title{
Fabrication of a novel catalyst reactor with improved strength and catalytic performance used for automotive exhaust treatment
}

\author{
Huangyue Cai
}

School of Materials Science and Engineering, Shanghai Jiao Tong University, Shanghai 200240, China

Fangwei Guo*

School of Materials Science and Engineering, Shanghai Jiao Tong University, Shanghai 200240, China

Xing Zhang

Aerospace System Engineering Shanghai, Shanghai 201108, China

$$
\text { Xin Wang }
$$

Solar Space Co. Ltd., Xuzhou 221699, China

$$
\mathrm{Li} \mathrm{Hu}
$$

Aerospace System Engineering Shanghai, Shanghai 201108, China

$$
\text { Xiaofeng Zhao }
$$

School of Materials Science and Engineering, Shanghai Jiao Tong University, Shanghai

$$
\text { 200240, China }
$$

\section{Ping Xiao}

School of Materials, University of Manchester, Manchester M13 9PL, United Kingdom

* Corresponding author: Fangwei Guo

Email: fwguo2014@sjtu.edu.cn; Tel: +86-21-54742561; Fax: +86-21-54742561 


\begin{abstract}
Yttria-stabilized zirconia hollow fibers (YSZ-HFs) containing radial wall microchannels with one end opening on the inner surface were prepared, and robust reactor modules of YSZ-HFs for automotive emission were prepared by bundling fibers with cement glue. 100\% open-cell ratio and the unique microstructure of the YSZ-HFs catalytic reactor facilitated deposition of $\mathrm{LaMnO}_{3}$ three-way catalysts. Compared with the commonly used cordierite $\left(2 \mathrm{MgO}-2 \mathrm{Al}_{2} \mathrm{O}_{3}-5 \mathrm{SiO}_{2}\right)$ honeycombs $(\mathrm{CHs})$, the $\mathrm{YSZ}-\mathrm{HFs}$ improved the reducibility and sintering resistance of the attached catalyst film. Higher effective conversion of $\mathrm{CO}$ and NO was found in the YSZ-HFs samples in comparison to the CHs samples. Moreover, the YSZ-HFs samples achieving higher flexural strength $(\sim 135 \mathrm{MPa})$ can better preserve the mechanical properties and the integrity of the catalyst film after 200 thermal shock cycles at $900{ }^{\circ} \mathrm{C}$, due to the small thermal mismatch between the YSZ-HFs and the catalysts, as well as the intrinsic merit of zirconia.
\end{abstract}

Key words: automotive exhaust, ceramic hollow fiber reactor, redox property, thermal shock resistance, flexural strength 


\section{Introduction}

Automotive exhaust is regarded as one of the major sources of the atmospheric pollution. ${ }^{1,2}$ The catalytic converters employed nowadays for automotive exhaust treatment usually consist of two parts: ceramic monoliths and supported catalysts. ${ }^{3}$ The ceramic monoliths are composed of interconnected repeating cells, and always have a honeycomb like crosssection. ${ }^{4}$ The lower the pressure drop, the lower the energy loss. ${ }^{5}$ It leads to an important advantages of the monolith, which is the low flow resistance and then low pressure drop. The extrusion process, which is the most commonly used method for making ceramic monolith, must be satisfied first with an adequate plastic paste to permit extrusion then immediate solidification to form the monolith shape. Moreover, there is a compromise for the ceramic monoliths between to achieve an elevated mechanical property and to have high specific surface area, for which purpose generally permanent agglomerations are added. ${ }^{6}$

Ceramic hollow fibers (CHFs) have served as catalyst support in catalytic hollow fibers membrane reactors, and succeeded in several catalytic processes. ${ }^{7,8}$ The CHFs are usually prepared by a combined non-solvent induced phase inversion and sintering method, which allows a flexible tuning over morphologies and microstructures, and a wide range of ceramic materials can be adopted. ${ }^{9-12}$ The suspension required for the phase inversion technique has a better fluidity, thus allowing easier extrusion. Besides, the non-solvent induced solidification process is tolerant of the rheological property of suspension, 
suspensions within a considerable viscosity range can be solidified. ${ }^{9}$ CHFs usually consist of a large number of ordered micro-channels sandwiched between one or more sponge-like layer, which greatly increases the ratio of surface to volume. ${ }^{13}$ The catalytic performance of catalytic hollow fibers can be affected by the morphology of the hollow fiber substrate, the distribution of the catalyst, the configuration, and other factors. Gallegos-Suárez ${ }^{7}$ and García-García ${ }^{14}$ et al. investigated the effects of morphology for $\mathrm{Al}_{2} \mathrm{O}_{3}$ hollow fiber on the catalytic performance, their results indicated that the sponge-like structures benefited the formation of smaller catalyst particles, and compared with symmetric structures (consist entirely of sponge-like structure), asymmetric structures (consist of both sponge-like structure and microchannels) presented a better catalytic performance because of the improved heat- and mass-transfer efficiencies and the higher internal area provided by the micro-channels. An et al. ${ }^{15}$ prepared perovskite hollow fiber membrane modules by bonding the hollow fibers with another porous perovskite binder, which not only provided mechanical strength to the hollow fiber bundles, but also promoted the surface exchange rates. The results confirmed the feasibility of building a ceramic hollow fiber module by bonding them together.

Catalysts supports in the automotive exhaust catalytic converter are required to serve in very harsh operating conditions with temperatures exceeding $1000^{\circ} \mathrm{C}$, in this case ceramic materials with high melting temperature and resistance to oxidation are supposed to be appropriate. ${ }^{16}$ Furthermore, the crucial mechanical properties for the supports include 
strength and thermal shock resistance. The tensile and compressive strengths are important for packing loads, vibrations and road shocks during mobile applications. The requirement of thermal shock resistance results from the rapid temperatures changes experienced in automotive exhaust. Besides the physical and mechanical properties, the supports should also satisfy the requirement of having least impact on the catalytic activity. The chemical reaction and/or incorporation between the catalysts and supports may poison the catalyst and result in a degradation of catalytic activity. ${ }^{17,18}$

In this work, the yttria-stabilized zirconia hollow fibers (YSZ-HFs) were prepared by a combined non-solvent induced phase inversion and sintering method, $\mathrm{LaMnO}_{3}$ was incorporated as a three-way catalyst into the hollow fibers by the sol-gel Pechini method and then assembled as a catalytic converter for automotive exhaust treatment. The mechanical and catalytic performance of the hollow fibers were evaluated and compared with that of the cordierite honeycombs (CHs). The modules of YSZ-HFs were prepared by bundling fibers together to assess the feasibility of assembly and the subsequent mechanical properties.

\section{Experiments}

\subsection{Preparation of YSZ hollow fiber reactors}

The suspension for preparing YSZ-HFs was composed of $85.72 \mathrm{~g} 3 \mathrm{~mol} \%$ yttria-stabilized zirconia powder (3YSZ, >99.9\%, 200 nm, Jiangxi Fanmeiya Materials Co., Ltd.), 14.28 g 
PESf (BD-5, Beishide Chemical Reagent Factory), 71.42 g N-methyl-2-pyrrolidone (NMP) (AR Grade, Sinopharm, China), $22.18 \mathrm{~g}$ methanol (AR Grade, Sinopharm, China), $6.4 \mathrm{~g}$ PEG-400 (AR Grade, Sinopharm, China). The raw materials were mixed by high energy ball milling for $24 \mathrm{~h}$ to ensure a uniform distribution of YSZ particles. After milling, the suspension was transferred into a sealed vessel and degassed under vacuum for $1 \mathrm{~h}$ to remove the bubbles induced by milling. Then the suspension was extruded by an absolute nitrogen pressure of $0.15 \mathrm{MPa}$ through a spinneret with the external and inner diameter of 1.2 and $0.7 \mathrm{~mm}$ into a water coagulation bath. The injection rate of internal coagulant was about $15 \mathrm{ml} / \mathrm{min}$. Tap water and $94 \mathrm{wt} \% \mathrm{NMP}$ aqueous solution were used as the external and internal coagulant respectively. The green hollow fibers formed were remained in the coagulation bath for $48 \mathrm{~h}$ to complete the phase inversion process. Then the greens were dried at room temperature and sintered at $1300{ }^{\circ} \mathrm{C}$ for $2 \mathrm{~h}$ (Carbolite furnace, UK) with a heating and cooling rate both of $5{ }^{\circ} \mathrm{C} / \mathrm{min}$ to achieve a proper mechanical property.

\subsection{Incorporation of catalysts}

The $\mathrm{LaMnO}_{3}$ catalyst was deposited using the sol-gel Pechini method. In the catalyst solution preparation, $53.681 \mathrm{~g}$ of $\mathrm{La}\left(\mathrm{NO}_{3}\right)_{3} \cdot 6 \mathrm{H}_{2} \mathrm{O}$ (AR Grade, Sinopharm, China) and $53.681 \mathrm{~g} \mathrm{Mn}\left(\mathrm{NO}_{3}\right)_{2}$ (50 wt\% solution, AR Grade, Sinopharm, China) were dissolved in 73.159 g deionized water. Citric acid (AR Grade, Sinopharm, China) was added to the solution in a molar ratio of 2:1 to the metal ions. After the citric acid was fully dissolved, ethylene glycol was added into the solution at a molar ratio 1:1.2 to the citric acid. 
The YSZ-HFs and CHs were completely immersed in the catalyst solution. Then the mixture of catalyst solution and catalyst supports was transferred into a sealing vessel and degassed under vacuum until there was no visible bubble, the vacuum was maintained for $12 \mathrm{~h}$ to make sure that the solution had infiltrated the supports sufficiently. After that, the deposited YSZ-HFs and CHs were dried at $60{ }^{\circ} \mathrm{C}$ for $12 \mathrm{~h}$ and then polymerized at $115^{\circ} \mathrm{C}$ for $12 \mathrm{~h}$. The xerogel formed during the polymerization process was calcined at $800{ }^{\circ} \mathrm{C}$ for $1 \mathrm{~h}$ to complete the crystallization. The amount of catalyst deposited on the YSZ hollow fiber and honeycomb was determined by weighing before and after the deposition and calcined steps. The $\mathrm{LaMnO}_{3}$ powder were also prepared by fresh catalyst sol-gel solution under the same condition to confirm the crystallization process.

\subsection{Catalytic performance}

The catalytic performances of the catalyst deposited YSZ-HFs and CHs were evaluated using a purpose-built experimental apparatus (as shown in Figure 1). The YSZ-HFs and $\mathrm{CHs}$ were assembled in alumina tubes and the junctions were sealed with cement glue to ensure the airtightness. The alumina tubes were then inserted in the furnace and centered in the uniform heating zone $(10 \mathrm{~cm})$, the temperature was measured by a thermocouple adjacent to the alumina tubes. The feed stream contained $\mathrm{NO}(0.08 \mathrm{vol} \%), \mathrm{C}_{3} \mathrm{H}_{8}(0.2 \mathrm{vol} \%)$, $\mathrm{CO}(1.8 \mathrm{vol} \%), \mathrm{CO}_{2}(10 \mathrm{vol} \%)$, and $\mathrm{O}_{2}(1.81 \mathrm{vol} \%)$, balanced with $\mathrm{N}_{2}$. The composition of reacted gas from the reactor was analyzed by gas chromatographs (GC-14B, Shimadzu). The catalytic performance test was investigated at $100{ }^{\circ} \mathrm{C}-900{ }^{\circ} \mathrm{C}$ with $100{ }^{\circ} \mathrm{C}$ intervals, 
under atmospheric pressure. The gas hourly space velocity (GHSV) was $30000 \mathrm{~h}^{-1}$, defined as volumetric flow rate of reactants $\left(\mathrm{m}^{3} / \mathrm{h}\right)$ over total volume of catalytic reactor $\left(\mathrm{m}^{3}\right)$. The catalytic efficiency was evaluated based on effective conversion of $\mathrm{CO}, \mathrm{NO}$ and $\mathrm{C}_{3} \mathrm{H}_{8}$.

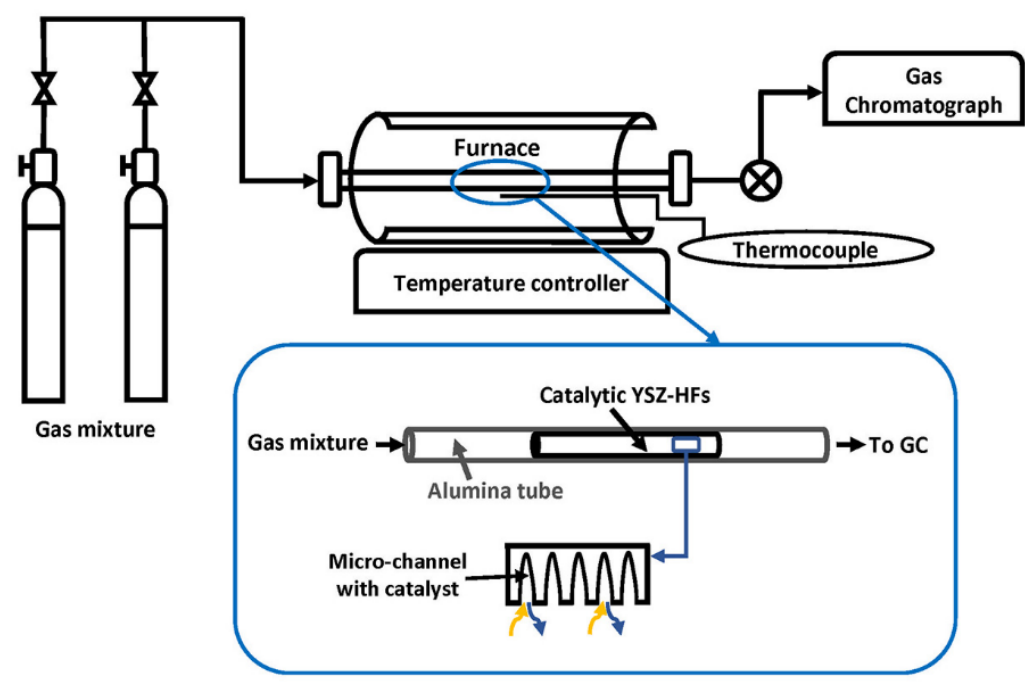

Figure 1. Schematic representation of experimental apparatus of catalytic performance.

\subsection{Mechanical performance and thermal shock resistance}

The mechanical performance of the two supports was measured with four points flexure tests by a mechanical testing machine (ZWICK, Roell Z020). The outer span was $40 \mathrm{~mm}$ and the inner one was $20 \mathrm{~mm}$. All the samples were placed horizontally on the support, and the loading speed of pressure head was $0.5 \mathrm{~mm} / \mathrm{min}$ with a preload of $0.2 \mathrm{~N}$. The four points flexural strength was calculated by: $\sigma=M \cdot c / I$, where the $\sigma$ was flexural strength, $M$ was the applied moment, $c$ was the distance from neutral axis, $I$ was the second area moment (moment of inertia). 
In order to simulate the real service condition, the four-points flexure tests were also performed on the two different supports with the minimum configuration of modules. The modules of CHs were cut from a monolith and contain four channels, and the modules of YSZ-HFs were prepared by bundling three fibers with commercial cement glue.

Thermal shock tests were conducted by placing the YSZ-HFs and CHs in a cyclic heating and cooling process from room temperature to a peak temperature of $900{ }^{\circ} \mathrm{C}$. The samples were maintained at peak temperature for $90 \mathrm{~s}$ and then cooled down in $90 \mathrm{~s}$ in flowing air. Four points flexure tests were conducted with the samples which went through $0,50,100$, and 200 cycles to test the thermal shock resistance of the supports, and the anti-sintering property of the catalysts was evaluated by the coarsening of the catalyst particles during the thermal shocks.

\subsection{Characterization}

The microstructure of supports with and without catalyst deposition were observed by using a scanning electron microscopy (MAIA3, TESCAN). The samples were gold coated for the electron micrographs of inner and outer surface, as well as the fracture surfaces. The porosity of samples was obtained by image analysis (Image J), and the elastic modulus was calculated with the porosity by the MacKenzie model. ${ }^{19}$

X-ray diffraction (XRD) patterns of the deposited YSZ-HFs were performed on the segments of fibers using a Rigaku SmartLab $(\mathrm{Cu} \mathrm{K} \alpha)$ with a $2 \theta$ degree range from $10^{\circ}$ to 
$70^{\circ}\left(5^{\circ} / \mathrm{min}\right)$. The same XRD measurements were also performed on the $\mathrm{LaMnO}_{3}$ powders.

X-ray photoelectron spectroscopy (XPS) analysis were performed on both the inner and outer surface of YSZ-HFs deposited with $\mathrm{LaMnO}_{3}$ (Thermo ESCALAB 250). The samples were out-gassed under vacuum $\left(10^{-5} \mathrm{~Pa}\right)$ and then introduced into the analysis chamber $\left(10^{-}\right.$

${ }^{6} \mathrm{~Pa}$ ). The spot size was approximately $200 \mu \mathrm{m}$ in diameter. The resolution for the general spectra and element spectra was fixed at 4. Binding energy (BE) values were referred to the $\mathrm{C}-(\mathrm{C}, \mathrm{H})$ component of $\mathrm{C} 1 \mathrm{~s}$ peak fixed at $282.8 \mathrm{eV}$.

The catalyst deposited YSZ-HFs and CHs were crushed into pieces for temperature program reduction (TPR) analysis (AutoChem II 2920, Micromeritics). $5 \mathrm{mg}$ of catalyst was used for both the two supports by using the catalyst mass concentration obtained from previous step. The samples were loaded in a quartz U-tube reactor and pretreated under an Ar flow $(30 \mathrm{ml} / \mathrm{min})$ at $120{ }^{\circ} \mathrm{C}$ to remove the adsorbed water. After cooled to $50{ }^{\circ} \mathrm{C}$, the samples were exposed to a flow of $5 \% \mathrm{H}_{2} / \mathrm{Ar}(30 \mathrm{ml} / \mathrm{min})$ and the temperature were raised to $1000{ }^{\circ} \mathrm{C}$ at a rate of $10{ }^{\circ} \mathrm{C} / \mathrm{min}$.

\section{Results and discussion}

\subsection{Microstructure of the YSZ hollow fibers}

Figure 2 represented images of the YSZ-HFs prepared by a non-solvent induced phase inversion method and sintered at $1300{ }^{\circ} \mathrm{C}$ for $2 \mathrm{~h}$. The average inner and outer diameter of the YSZ-HFs were $374.42 \mu \mathrm{m}$ and $581.27 \mu \mathrm{m}$ respectively. The asymmetric YSZ-HFs 
consisted of two regions: a dense outer skin layer consisting less than $10 \%$ of the section thickness of the hollow fiber, and plenty of radial micro-channels initiated beneath the skin layer and penetrated through the fiber, leaving large openings about $10 \mu \mathrm{m}$ on the inner surface (Figure 2b). Moreover, there was a thin wall possessing a packed-pore cellular structure separating the radial micro-channels. The fractured surface of the wall between the micro-channels in Figure $2 \mathrm{c}$ revealed that the fracture mode of YSZ-HFs was transgranular, which usually signified a good mechanical performance. Figure $2 \mathrm{~d}$ showed the outer surface of the sintered sample, YSZ particles were closely connected to each other to form a smooth surface without crack, but some voids remained on the outer surface. The micro-channels were ideal for catalyst deposition because they brought a significantly increase in the surface area, each channel could act as a micro-reactor which promoted the heat- and mass- transfer efficiencies. ${ }^{20}$ Furthermore, the interparticle spaces inside the cellular structures could also provide sites for the catalyst deposition.

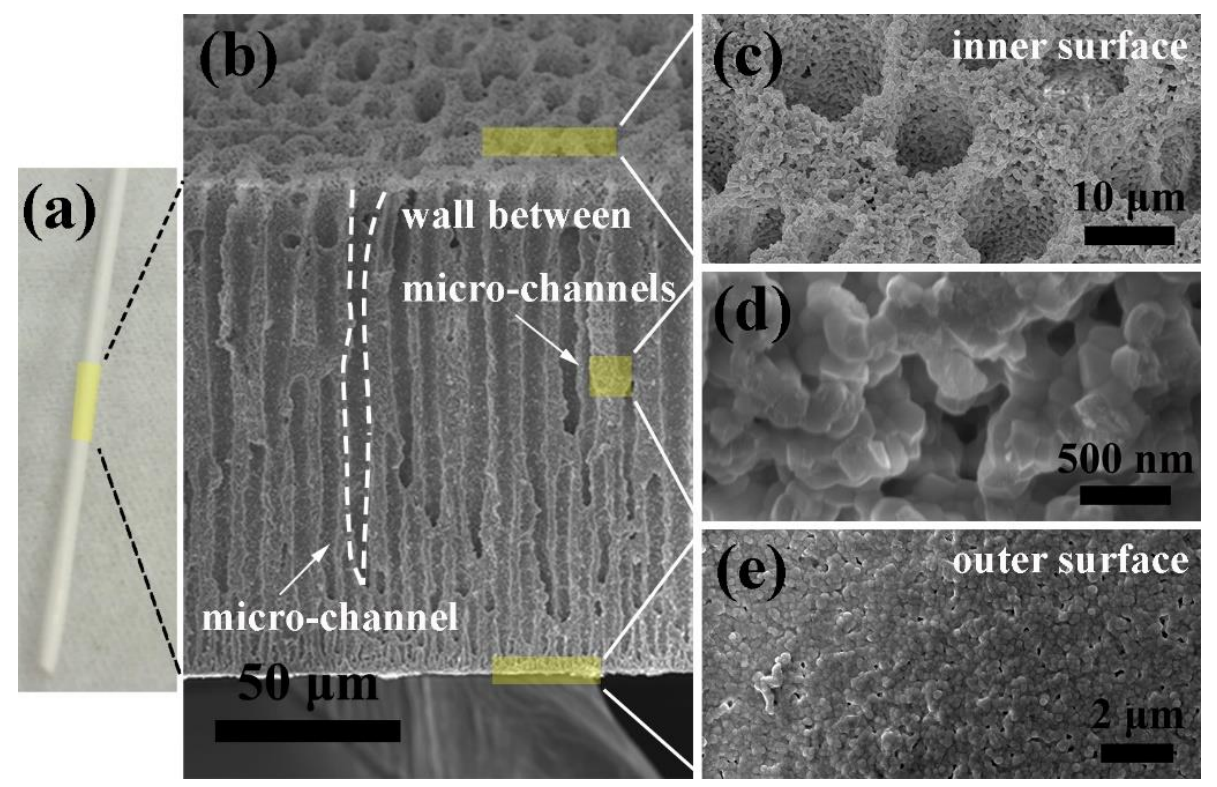


Figure 2. Images of YSZ-HFs prepared by a combined phase inversion/sintering method. (a) Photographic images of a bare YSZ-HF; (b-e) SEM micrographs of the bare YSZ-HFs: (b) global cross-section along the axis; (c) voids on the inner surface; (d) wall between the micro-channels; (e) outer surface.

\subsection{Catalytic performance}

The incorporation of the $\mathrm{LaMnO}_{3}$ catalyst was carried out using the sol-gel Pechini method, the catalyst loadings were $4.5 \%$ and $3.6 \%$ for the YSZ-HFs and the CHs respectively. The diffractograms of $\mathrm{LaMnO}_{3}$ powder (Figure 3b) showed the presence of $\mathrm{LaMnO}_{3.15}$ phase. ${ }^{21,22}$ The pattern presented characteristic diffraction peaks of the target product, which indicated that the $\mathrm{LaMnO}_{3}$ catalyst could be crystallized under the given experimental conditions. The XRD analyses were also carried out on the YSZ-HFs before and after the catalyst deposition (Figure 3a). The comparison of XRD patterns of the bare and catalyst deposited samples confirmed the presence of the $\mathrm{LaMnO}_{3}$ catalyst (signed with red stars) on the YSZ-HFs. 


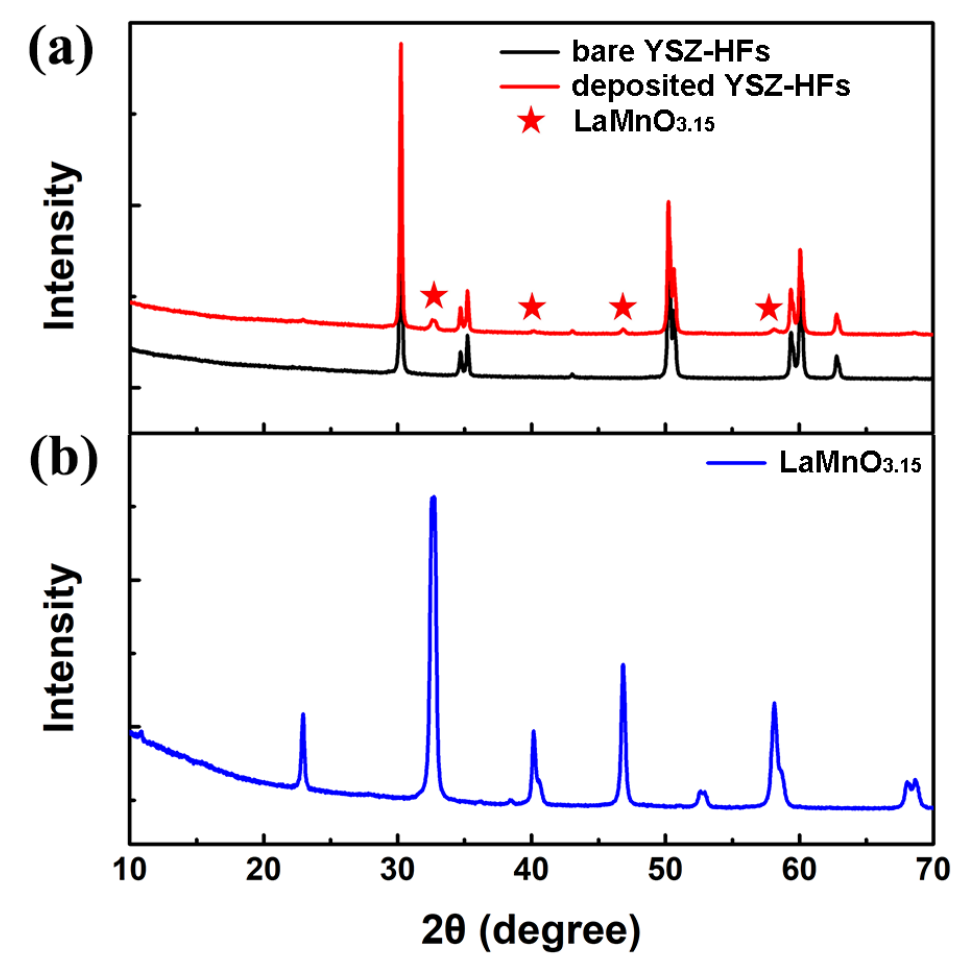

Figure 3. XRD patterns of (a) YSZ-HFs before and after the catalyst deposition; (b) $\mathrm{LaMnO}_{3}$ powder prepared by the fresh catalyst sol-gel solution.

For obtaining the valence state of the deposited catalyst, XPS spectra were measured. Peaks resembling typical La $3 \mathrm{~d}$ and $\mathrm{Mn} 2 \mathrm{p}$ were recorded on the outer surface of catalyst deposited YSZ-HFs and presented in Figure 4. The La 3d was featured by a double peak for each component ( $\operatorname{La} 3 \mathrm{~d}_{3 / 2}$ and La $\left.3 \mathrm{~d}_{5 / 2}\right)$. The Mn $2 p$ peak split into 2 components. The binding energies of these elements present in deposited catalyst were listed as following: $641.9 \mathrm{eV}$ for $\mathrm{Mn} 2 \mathrm{p}_{3 / 2}, 834.5 \mathrm{eV}$ for $\mathrm{La} 3 \mathrm{~d}_{5 / 2}, 529.5 \mathrm{eV}$ for $\mathrm{O}(\mathrm{I}) 1 \mathrm{~s}$ and $531.4 \mathrm{eV}$ for $\mathrm{O}(\mathrm{II}) 1 \mathrm{~s}$, which agreed with a previous study. ${ }^{22}$ 

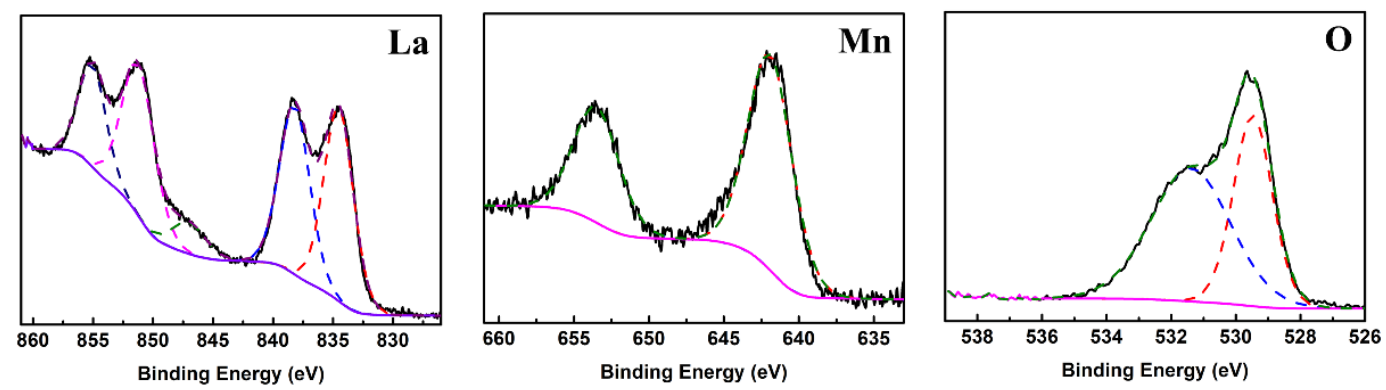

Figure 4. XPS spectra of the $\mathrm{LaMnO}_{3}$ deposited on the outer surface of YSZ-HFs.

Table 1 listed the relative surface atomic ratios of the catalyst deposited YSZ-HFs obtained by XPS. The atomic ratios were calculated from the corresponding $\mathrm{La} 3 \mathrm{~d}, \mathrm{Mn} 2 \mathrm{p}$ and $\mathrm{Zr}$ $3 \mathrm{~d}$ spectra, the corresponding XP sensitivity factors were considered. For both the inner and outer surface of the $\mathrm{YSZ}-\mathrm{HFs}$, the $\mathrm{La} / \mathrm{Mn}$ and $\mathrm{La} / \mathrm{Zr}$ atomic ratio larger than 1 indicated that the sample surfaces were enriched by La. La accumulation on the surface was likely due to the formation of $\mathrm{La}_{2}\left(\mathrm{CO}_{3}\right)_{3}, \mathrm{La}(\mathrm{OH})_{3}$ and/or amorphous $\mathrm{La}_{2} \mathrm{O}_{3}$ domains together with the $\mathrm{LaMnO}_{3} .{ }^{23}$ It is worth mentioning that the $\mathrm{La} / \mathrm{Zr}$ atomic ratio of outer surface was larger than that of the inner surface, indicating a better coverage of catalyst on the outer surface. $^{22}$ The catalyst loading of the inner surface by the sol-gel infiltration procedure strongly depended on the contact angle and the pore geometry. ${ }^{24,25}$ However, the roughness of the inner surface could weaken the wettability, ${ }^{26}$ resulting in a poorer coverage of catalyst film consequently.

Table 1. Quantitative determination of the surface atomic ratios via XPS for the $\mathrm{LaMnO}_{3}$ deposited YSZ-HFs. 
Surface atomic ratio of the catalyst deposited YSZ hollow fiber

\begin{tabular}{c|c|c}
\hline & $\mathrm{La} / \mathrm{Mn}$ & $\mathrm{La} / \mathrm{Zr}$ \\
\hline Inner surface & 1.74 & 0.55 \\
\hline Outer surface & 1.53 & 2.34 \\
\hline
\end{tabular}

The effect of the catalyst support on the reduction properties of the perovskite catalysts was studied by $\mathrm{H}_{2}$-TPR. Figure 5 showed the TPR profiles of catalyst deposited YSZ-HFs and CHs. The several reduction peaks observed here were corresponding to the surface (small peaks at $\mathrm{T}<400{ }^{\circ} \mathrm{C}$ ) and bulk ( $\mathrm{T}$ at $\sim 500-600{ }^{\circ} \mathrm{C}$ and $\sim 700-900{ }^{\circ} \mathrm{C}$ ) reduction of the catalysts. ${ }^{27}$ However, only the catalyst deposited YSZ-HFs showed a weak peak before $400{ }^{\circ} \mathrm{C}$. In general, these reactive surface oxygens could be located either at some surface defects or correspond to oxygen adsorption on centers at some perovskite faces. Disappearance of the low-temperature peak suggested a less reactive densely packed structure of the catalyst. The peaks at $500-600{ }^{\circ} \mathrm{C}$ could be assigned to the removal of the non-stoichiometric oxygen accommodated within the lattice which could be ascribed to $\mathrm{Mn}^{4+} \rightarrow \mathrm{Mn}^{3+} .28$

Besides the catalyst, there was no excess oxygen in the cordierite, and non-stoichiometric oxygen vacancies were presented only within the YSZ materials. The oxygen vacancies were not helping the reduction process, yet they could be beneficial to the decomposition of $\mathrm{NO}_{\mathrm{x}} \cdot{ }^{29}$ The second peak corresponding to the bulk reduction of catalyst was assigned to the reduction of $\mathrm{Mn}^{3+}$ to $\mathrm{Mn}^{2+} .30$ 
The color of the samples, initially black, became grey after reduction at $1000{ }^{\circ} \mathrm{C}$, suggesting that new phases were formed. The lower temperature peak position for the catalyst deposited YSZ-HFs indicated a lower activation energy for the reduction of $\mathrm{Mn}^{3+}$ to $\mathrm{Mn}^{2+}$, which could be contributed by the lower incorporation of manganese into the zirconia lattice, favoring the target perovskite phase formation. ${ }^{17}$ The ability of the catalyst to maintain redox properties could be modified by the strong interactions between the support and catalyst, studies had shown that zirconia was beneficial to increase the catalytic activity of the perovskite catalyst. . $2,31,32^{2}$

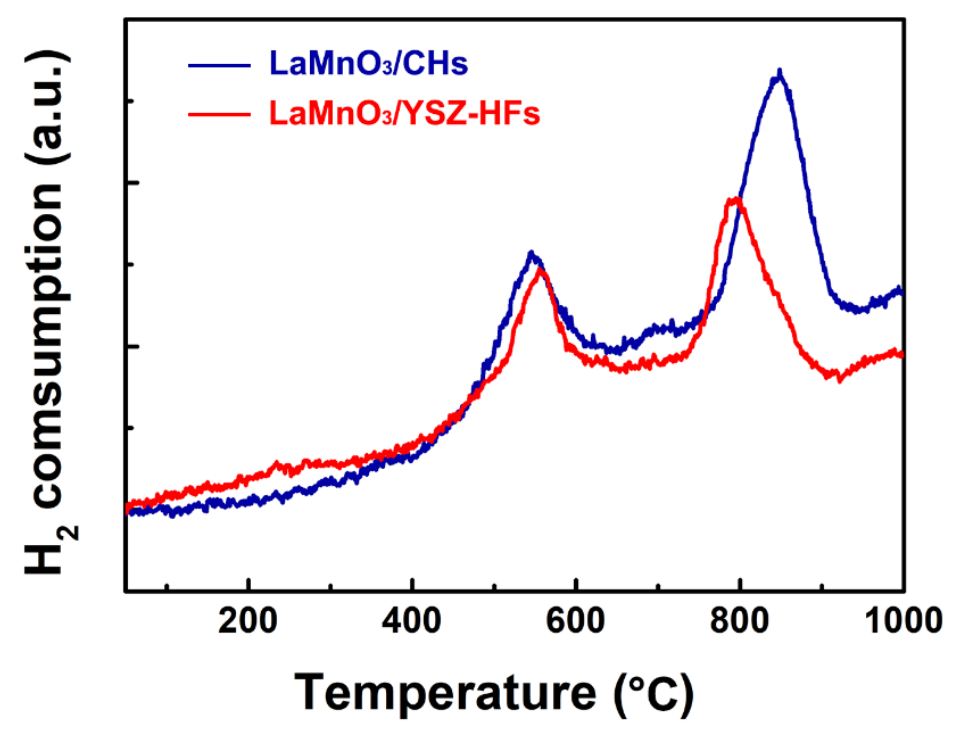

Figure 5. Temperature program reduction results of catalyst deposited CHs and YSZ-HFs.

The catalytic performance the YSZ-HFs and the CHs were evaluated based on the effective conversions of three main pollutants. Figure 6 showed the catalytic performance of the two catalysts supports. Apparently, effective conversions of the pollutants increased with temperature, and although the $\mathrm{C}_{3} \mathrm{H}_{8}$ conversion of YSZ-HFs was slightly lower than that 
of the $\mathrm{CHs}$ before $700{ }^{\circ} \mathrm{C}$, it reached a complete purification faster. The NO conversion of YSZ-HFs started to show an advantage from $500{ }^{\circ} \mathrm{C}$ and maintained until a complete conversion. Moreover, the CO conversion of YSZ-HFs was higher than that of the CHs throughout the process.

The CO was oxidized by the dissolved oxygen species adsorbed on the catalysts surface, ${ }^{27}$ the zigzag catalyst film of YSZ-HFs promoted the adsorption of oxygen and CO by providing more corners/steps. ${ }^{7}$ Moreover, the reactive surface oxygens located on the catalytic YSZ-HFs could promote the low temperature oxidation of CO. ${ }^{33}$ Meanwhile, the catalyst film of $\mathrm{CHs}$ featured by faces/planes provided more adjacent sites, which were necessary for the $\mathrm{C}_{3} \mathrm{H}_{8}$ adsorption, ${ }^{7}$ resulting in a higher $\mathrm{C}_{3} \mathrm{H}_{8}$ conversion of $\mathrm{CHs}$ before $700{ }^{\circ} \mathrm{C}$. However, the participation of lattice oxygen could compensate the depletion of surface oxygen, maintaining the $\mathrm{C}_{3} \mathrm{H}_{8}$ conversion. The lower desorption temperature of lattice oxygen was the possible reason for the higher $\mathrm{C}_{3} \mathrm{H}_{8}$ conversion of catalytic YSZHFs above $700{ }^{\circ} \mathrm{C}$. The surface oxygen vacancies acted as the critical deoxidizer and provided anchoring sites for NO. ${ }^{27}$ Both the catalysts and YSZ were sources of the oxygen vacancies,${ }^{34}$ therefore, the YSZ-HFs were able to maintain a higher NO conversion. The results also indicated that the widely opened radial micro-channels of the YSZ-HFs could provide an ideal flow of reactants, significantly reducing the diffusion limitation and consequently allowing a more efficient interaction between the catalysts and the reactants. ${ }^{35}$ 


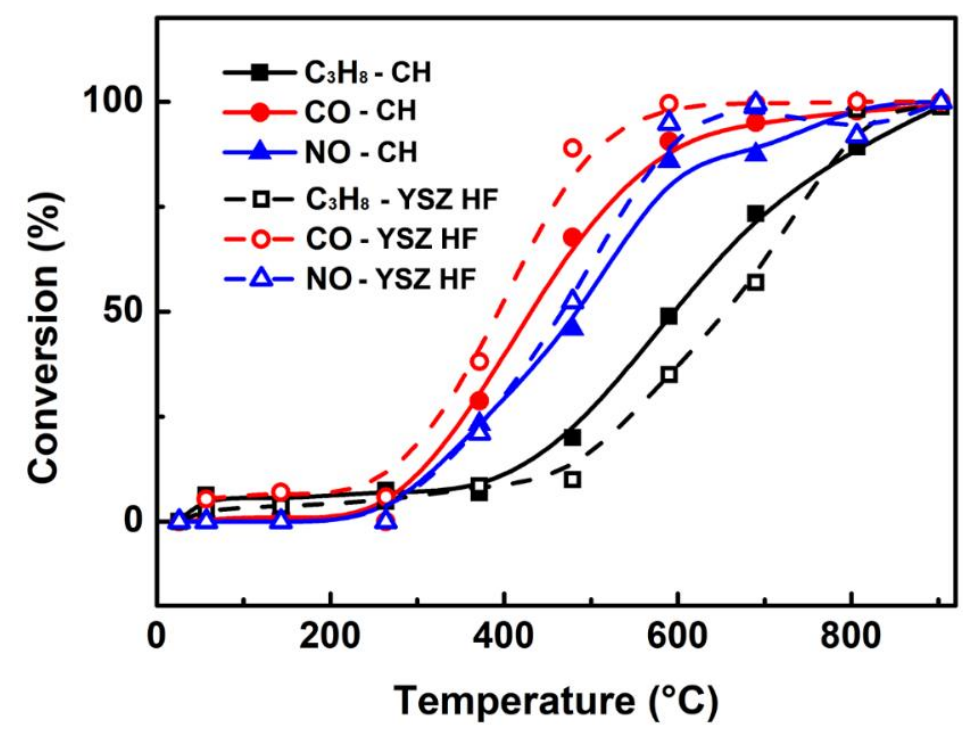

Figure 6. Temperature-dependent effective conversions of $\mathrm{C}_{3} \mathrm{H}_{8}, \mathrm{CO}$ and $\mathrm{NO}$ of the catalyst deposited YSZ-HFs and CHs.

\subsection{Thermal shock resistance}

Supports used in the automotive exhaust catalytic converter can experience a rapidly changing temperature from room temperature to over $1000{ }^{\circ} \mathrm{C}$ accompanied with thermal shock. Figure 7 presented the flexural strength of the YSZ-HFs and the CHs after different cycles of the thermal shock tests, the flexural tests were performed on the single fiber samples for YSZ-HFs, and the $\mathrm{CHs}$ was cut into bar samples containing a single channel for tests.

The flexural strengths of the YSZ-HFs were about three times those of the CHs for both the bare and catalyst deposited samples. The strength of bare YSZ-HFs was approximately $135 \mathrm{MPa}$, which was also much higher than that of similar alumina fibers in the previous 
study. ${ }^{8}$ During bending tests, the maximum tensile stress located on the outer surface of samples, and the volume under maximum tensile stress was smaller in the hollow cylinder than that in the square tube, suggesting a higher fracture strength of the hollow cylinder (namely, the YSZ-HFs samples). ${ }^{36}$ Moreover, the theoretical fracture strength of brittle materials was approximately proportional to the elastic modulus. ${ }^{37}$ The elastic modulus of YSZ-HFs calculated by porosity was higher that of the CHs, which indicated that the former can achieve higher strength. However, the fracture strength of YSZ-HFs was also influenced by the pore size and its degree of anisotropy. ${ }^{38,39}$ Stress concentration severely occurred at anisotropic pores, and resulted in the crack initiation. ${ }^{38}$ Furthermore, the high porosity of YSZ-HFs could reduce the free energy expended in creating the new crack surfaces, favoring the crack propagation. Therefore, the higher fracture strength of YSZHFs was attributed to the geometry and higher elastic modulus of the YSZ material.

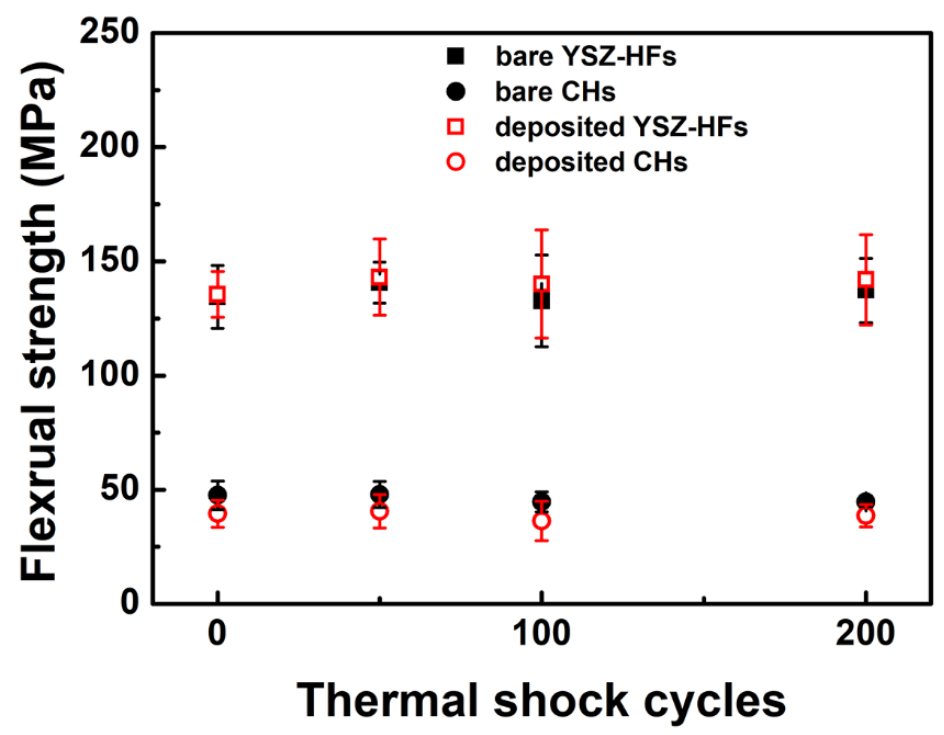

Figure 7. Flexural strengths of the YSZ-HFs and CHs (bare and catalyst deposited) after 
different cycles of the thermal shock.

There was no obvious decline of strength with the increasing cycles of thermal shock for all the samples. However, the strengths of catalyst deposited CHs were slightly weaker than those of the bare samples, whilst the deposited and bare YSZ-HFs were basically of the same strength and some of the deposited samples were even higher. The microstructures of the fresh catalyst deposited samples and ones after 200 cycles of thermal shock were shown in Figure 8.
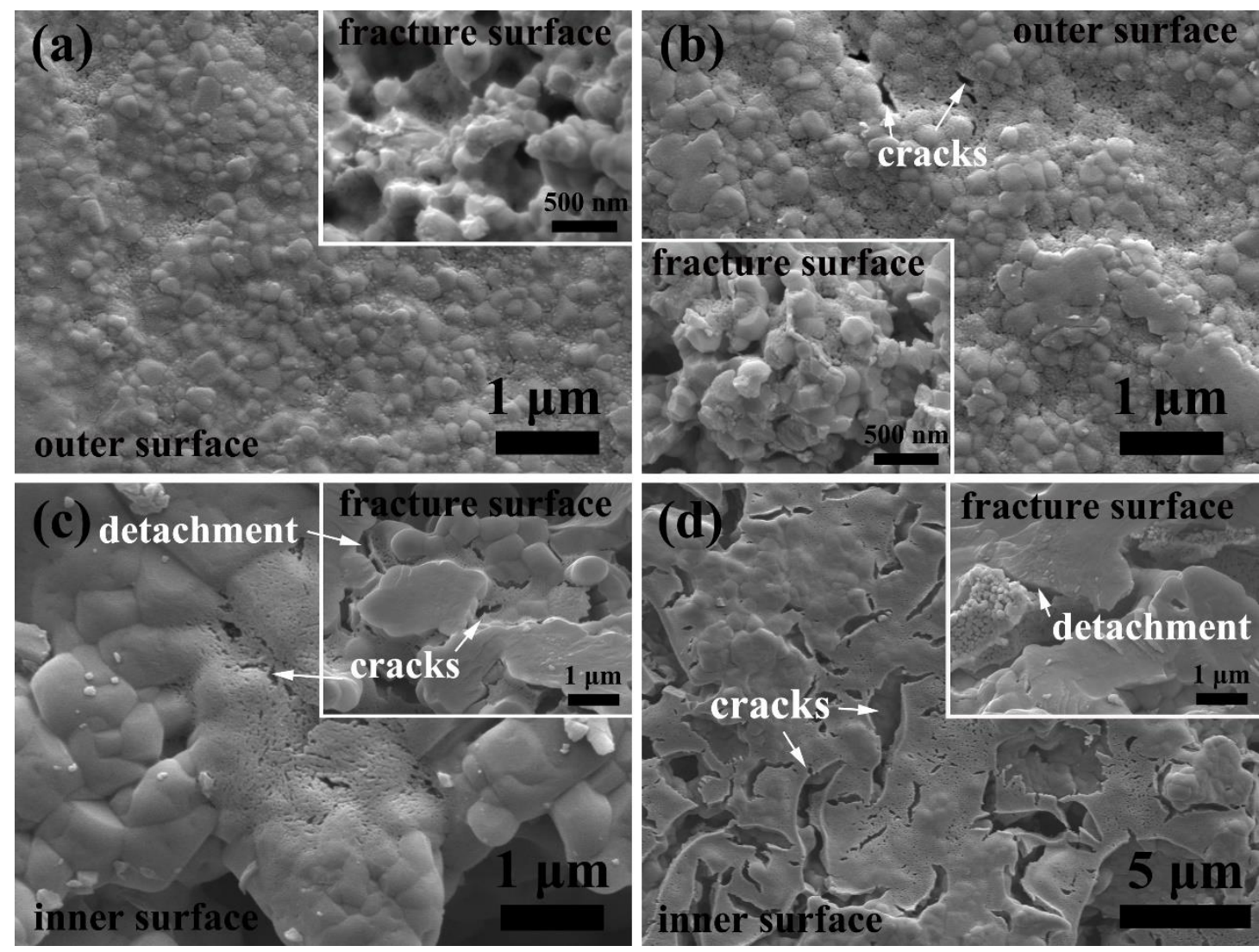

Figure 8. The SEM images of the microstructures of the fresh catalyst deposited (a) YSZ-

HFs and (c) CHs; microstructures of catalyst deposited (b) YSZ-HFs and (d) CHs after 200 
cycles of thermal shock.

For fresh catalyst deposited samples (Figure $8 \mathrm{a}$ and $\mathrm{c}$ ), the catalysts formed a thin film covering the surface of supports. The catalyst films adhered on the particles of YSZ-HFs and evenly distributed over the interparticle pores. After 200 cycles of thermal shock, the catalyst films on the outer surface of YSZ-HFs cracked slightly, and the catalyst particles over the fracture surface of HFs (inserted SEM images in Figure 8b) coarsened. In contrast to the YSZ-HFs, the catalyst films on fresh deposited CHs cracked without any thermal shock and the catalyst particles over the fracture surface were larger than that of the YSZHFs. This phenomenon could be explained by the fact that during the impregnation process, the larger the voids, the more sol-gel solution filled in, allowing the perovskite particles to grow larger during the polymerization process. Moreover, the catalyst deposited on the CHs cracked and detached significantly after 200 cycles of thermal shock. The thermal expansion coefficient (CTE) of the $\mathrm{LaMnO}_{3}$ was $11.2 \times 10^{-6} / \mathrm{K}$ while that of the cordierite was around $1.5 \times 10^{-6} / \mathrm{K},{ }^{40,41}$ the significant discrepancy of CTE between the catalyst and the cordierite was supposed to cause considerable stresses during the thermal shock. The catalyst films were subjected to tensile stresses during the cooling process because of the higher CTE, and the stresses could weaken the adhesion between the catalysts and supports, resulting in the detachment of catalyst. The tensile stresses could promote the grain growth as well, ${ }^{42}$ which explained the significantly coarsening of catalyst particles over the fracture surface of CHs in Figure 8d. Considering that the CTE of YSZ was around $10.5 \times 10^{-6} / \mathrm{K},{ }^{40}$ 
which was close to that of the $\mathrm{LaMnO}_{3}$, the CTE mismatch stress between the catalyst and YSZ-HFs would be much smaller. The coarsening of catalyst particles and the cracking of catalyst films were less for the YSZ-HFs after 200 cycles of thermal shocks when compared with $\mathrm{CHs}$, benefited from the smaller CTE mismatch stresses. Besides, an appropriate roughness of the substrate could enhance the bonding between the thin films and the substrates by trapping the cracks, ${ }^{43}$ in this case the planar interfaces between the catalyst films and the CHs lacked the ability to prevent crack extending.

Furthermore, the micro-cracks caused by the CTE mismatch stress may also be responsible for the degradation of flexural strength of the catalyst deposited cordierite samples.

\subsection{Modules of catalyst supports}

In order to evaluate the mechanical performance under realistic working condition, four points flexure tests were also performed with the minimum configuration of modules of two catalyst supports. The load-displacement curves of all the samples were shown in Figure 9a, and the inserted schematics represented the configuration of the two modules. The average fracture strength of YSZ-HFs modules was $146.31 \pm 12 \mathrm{MPa}$, while that of the CHs was $31.74 \pm 4.07 \mathrm{MPa}$. It was also noticed that every loading curve of the YSZ-HFs modules showed several pop-in discontinuities. Given that the YSZ-HFs were glued together with cement, the modules could be treated as a composite system for the analysis of mechanical performance. 


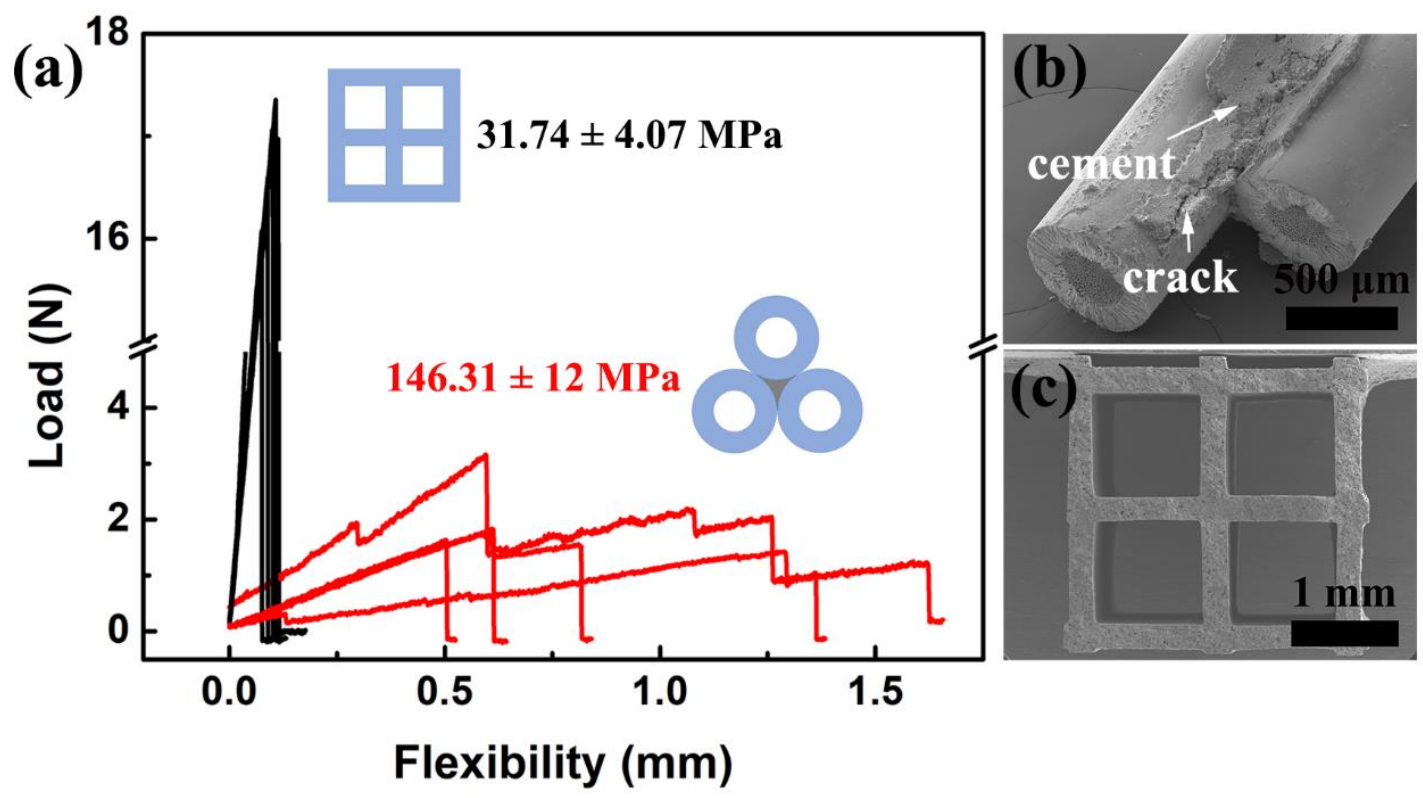

Figure 9. (a) Typical load-displacement curves of the minimum module of two supports in four-points flexure tests, inserted schematics represented the configuration of the two types of modules; fracture surfaces of (b) YSZ-HFs module and (c) CHs.

During the flexure tests, the maximum tensile stress was acting on the lower surface of the modules, the downside fibers were supposed to be fractured firstly, following by the crack propagation along the interface between the fibers and the cement. Final fracture occurred when the load reached the tensile strength of the upper fiber. The discontinuities on the load-displacement curves were contributed by a discontinuous fracture, each pop-in on the load-displacement curve was corresponding to a redistribution of stress across the cross section of modules. The fracture surfaces in Figure $9 \mathrm{~b}$ provided evidence of the crack deflection and the debonding between the fiber and cement, which agreed with the fracture micro-mechanisms. ${ }^{44}$ Most of the cracks were located in the cement rather than the YSZHFs, indicating that the configuration of bundling could be beneficial to the mechanical 
performance by providing a bonding material to absorb the fracture energy. Compared with single samples, the strength of YSZ-HFs modules increased, which might come from the contribution of cement. The facture surfaces of $\mathrm{CHs}$ modules presented no stepped feature (shown in Figure 9c), and there were no corresponding discontinuities on the loaddisplacement curves as well.

In addition to the mechanical properties, the number of channels per square inch (cpsi) was also an important property for the three-way catalyst support. The cpsi coupled with wall thickness, mainly defined the geometric surface, a key factor for mass-transfer controlled reactions and pressure-drop. The cpsi of YSZ hollow fibers was calculated as about 2400, which was far more better than the best commercial products at present $\left(\right.$ Celor ${ }^{\circledR}$ substrates, Corning Inc., $900 \mathrm{cpsi})$. Although the wall thickness of YSZ hollow fibers was larger than commercial products, the micro-channels on the wall of hollow fibers could provide extra surface area for the catalytic reaction.

\section{Conclusions}

YSZ-HFs with asymmetric structure were prepared and used to develop an efficient catalytic hollow fiber reactor for the automotive exhaust treatment. The radially opened micro-channels of the hollow fibers facilitated the catalyst deposition, and the pack-pore cellular structures benefited a firmly combination of catalyst film. The catalytic YSZ-HFs

presented a better catalytic performance than that of the $\mathrm{CHs}$, which was the combined 
results of catalysts morphology and lower desorption temperature of lattice oxygen. As important requirements of catalyst supports for the automotive exhaust treatment, the flexural strength and thermal shock resistance of the YSZ-HFs showed significant advantages over those of the CHs, because of the good mechanical properties of YSZ materials, as well as a less thermal expansion mismatch between the catalyst and the YSZHFs. The low thermal mismatch could also contribute to the integrity and the sintering resistance of the catalyst films. Besides, the feasibility of bundling the YSZ-HFs into a module was evidenced with the four-points flexure tests. Higher mechanical strength compared with single fiber was achieved, which was attributed to the cement and the interfaces between fibers and cement.

\section{Acknowledgement}

This work was supported by the National Natural Science Foundation of China (Grant No. $51402058)$.

\section{References}

(1) Johnson, T. Vehicular Emissions in Review. SAE Int. J. Engines. 2013, 6, 699.

(2) Heck, R. M.; Farrauto, R. J. Automobile Exhaust Catalysts. Appl. Catal. A Gen.

2001, 221, 443 .

(3) Twigg, M. V. Progress and Future Challenges in Controlling Automotive Exhaust Gas Emissions. Appl. Catal. B Environ. 2007, 70, 2. 
(4) Heck, R. M.; Gulati, S.; Farrauto, R. J. The Application of Monoliths for Gas Phase Catalytic Reactions. Chem. Eng. J. 2001, 82, 149.

(5) Lakhwani, S.; Hughes, K. W. Evaluation of a Stronger Ultra Thin Wall Corning Substrate for Improved Performance. SAE Tech. Pap. 2005, 2005-01-1109.

(6) Avila, P.; Montes, M.; Miró, E. E. Monolithic Reactors for Environmental Applications: A Review on Preparation Technologies. Chem. Eng. J. 2005, 109, 11.

(7) Gallegos-Suárez, E.; García-García, F. R.; González-Jiménez, I. D.; Rodríguez-

Ramos, I.; Guerreo-Ruiz, A.; Li, K. Ceramic Hollow Fibres Catalytic Enhanced Reactors for Glycerol Steam Reforming. Catal. Today 2014, 233, 21.

(8) Gouveia Gil, A.; Wu, Z.; Chadwick, D.; Li, K. Microstructured Catalytic Hollow Fiber Reactor for Methane Steam Reforming. Ind. Eng. Chem. Res. 2015, 54, 5563.

(9) Kingsbury, B. F. K.; Li, K. A Morphological Study of Ceramic Hollow Fibre Membranes. J. Memb. Sci. 2009, 328, 134.

(10) Guo, F.; Chen, X.; Wang, G.; Zou, Z.; Wang, X.; Zhang, Q.; Zhao, X.; Xiao, P. Hollow Ceramic Microspheres Prepared by Combining Electro-Spraying with NonSolvent Induced Phase Separation Method: A Promising Feedstock for Thermal Barrier Coatings. Mater. Des. 2018, 139, 343.

(11) Meng, X.; Yang, N.; Gong, X.; Yin, Y.; Ma, Z. F.; Tan, X.; Shao, Z.; Liu, S. Novel Cathode-Supported Hollow Fibers for Light Weight Micro-Tubular Solid Oxide Fuel Cells with an Active Cathode Functional Layer. J. Mater. Chem. A. 2015, 3, 1017.

(12) Tan, X.; Liu, N.; Meng, B.; Liu, S. Morphology Control of the Perovskite Hollow 
Fibre Membranes for Oxygen Separation Using Different Bore Fluids. J. Memb. Sci. 2011, 378, 308 .

(13) Kingsbury, B. F. K.; Wu, Z.; Li, K. A Morphological Study of Ceramic Hollow Fibre Membranes: A Perspective on Multifunctional Catalytic Membrane Reactors. Catal. Today. 2010, 156, 306.

(14) García-García, F. R.; Li, K. New Catalytic Reactors Prepared from Symmetric and Asymmetric Ceramic Hollow Fibres. Appl. Catal. A Gen. 2013, 456, 1.

(15) An, R.; Song, J.; Li, Y.; Tan, X.; Sunarso, J.; Zhang, C.; Wang, S.; Liu, S. Bundling Strategy to Simultaneously Improve the Mechanical Strength and Oxygen Permeation Flux of the Individual Perovskite Hollow Fiber Membranes. J. Memb. Sci. 2017, 527, 137.

(16) Koltsakis, G. C.; Stamatelos, A. M. Catalytic Automotive Exhaust Aftertreatment. Prog. Energy Combust. Sci. 1997, 23, 1.

(17) Cimino, S.; Lisi, L.; Pirone, R.; Russo, G.; Turco, M. Methane Combustion on Perovskites-Based Structured Catalysts. Catal. Today 2000, 59, 19.

(18) A.Iglesias-Juez. Metal-Promoter Interface in $\mathrm{Pd} /(\mathrm{Ce}, \mathrm{Zr}) \mathrm{O}_{\mathrm{x}} / \mathrm{Al}_{2} \mathrm{O}_{3}$ Catalysts : Effect of Thermal Aging. J. Catal. 2004, 221, 148.

(19) Pabst, W.; Gregorová, E.; Tichá, G. Elasticity of Porous Ceramics - A Critical Study of Modulus-Porosity Relations. J. Eur. Ceram. Soc. 2006, 26, 1085.

(20) Liu, N.; Tan, X.; Meng, B.; Liu, S. Honeycomb-Structured Perovskite Hollow Fibre Membranes with Ultra-Thin Densified Layer for Oxygen Separation. Sep. Purif. Technol. 
2011, 80, 396.

(21) Isupova, L. A.; Alikina, G. M.; Tsybulya, S. V.; Salanov, A. N.; Boldyreva, N. N.;

Rusina, E. S.; Ovsyannikova, I. A.; Rogov, V. A.; Bunina, R. V.; Sadykov, V. A.

Honeycomb-Supported Perovskite Catalysts for High-Temperature Processes. Catal.

Today 2002, 75, 305.

(22) Arendt, E.; Maione, A.; Klisinska, A.; Sanz, O.; Montes, M.; Suarez, S.; Blanco, J.;

Ruiz, P. Structuration of $\mathrm{LaMnO}_{3}$ Perovskite Catalysts on Ceramic and Metallic Monoliths: Physico-Chemical Characterisation and Catalytic Activity in Methane Combustion. Appl. Catal. A Gen. 2008, 339, 1.

(23) Say, Z.; Dogac, M.; Vovk, E. I.; Kalay, Y. E.; Kim, C. H.; Li, W.; Ozensoy, E. Palladium Doped Perovskite-Based NO Oxidation Catalysts: The Role of Pd and B-Sites for $\mathrm{NO}_{\mathrm{x}}$ Adsorption Behavior via in-Situ Spectroscopy. Appl. Catal. B Environ. 2014, $154-155,51$.

(24) Bán, S.; Wolfram, E.; Rohrsetzer, S. The Condition of Starting of Liquid Imbibition in Powders. Colloids and Surfaces 1987, 22, 291.

(25) Shan, X.; Luo, L.; Chen, W.; Zou, Z.; Guo, F.; He, L.; Zhang, A.; Zhao, X.; Xiao, P. Pore Filling Behavior of YSZ under CMAS Attack: Implications for Designing Corrosion-Resistant Thermal Barrier Coatings. J. Am. Ceram. Soc. 2018, 101, 5756. (26) Herrera, M. A.; Sirviö, J. A.; Mathew, A. P.; Oksman, K. Environmental Friendly and Sustainable Gas Barrier on Porous Materials: Nanocellulose Coatings Prepared Using Spin- and Dip-Coating. Mater. Des. 2016, 93, 19. 
(27) Keav, S.; Matam, S.; Ferri, D.; Weidenkaff, A. Structured Perovskite-Based

Catalysts and Their Application as Three-Way Catalytic Converters-A Review.

Catalysts 2014, 4, 226.

(28) Ponce, S.; Peña, M. A.; Fierro, J. L. G. Surface Properties and Catalytic Performance in Methane Combustion of Sr-Substituted Lanthanum Manganites. Appl. Catal. B

Environ. 2000, 24, 193.

(29) Peña, M. A.; Fierro, J. L. G. Chemical Structures and Performance of Perovskite Oxides. Chem. Rev. 2001, 101, 1981.

(30) Royer, S.; Duprez, D.; Can, F.; Courtois, X.; Batiot-Dupeyrat, C.; Laassiri, S.;

Alamdari, H. Perovskites as Substitutes of Noble Metals for Heterogeneous Catalysis:

Dream or Reality. Chem. Rev. 2014, 114, 10292.

(31) Lin, K. Y. A.; Chen, Y. C.; Lin, T. Y.; Yang, H. Lanthanum Cobaltite Perovskite

Supported on Zirconia as an Efficient Heterogeneous Catalyst for Activating Oxone in

Water. J. Colloid Interface Sci. 2017, 497, 325.

(32) Colonna, S.; De Rossi, S.; Faticanti, M.; Pettiti, I.; Porta, P. Zirconia Supported La, Co Oxides and $\mathrm{LaCoO}_{3}$ Perovskite: Structural Characterization and Catalytic $\mathrm{CO}$ Oxidation. J. Mol. Catal. A Chem. 2002, 180, 161.

(33) Labhsetwar, N. K.; Watanabe, A.; Biniwale, R. B.; Kumar, R.; Mitsuhashi, T. Alumina Supported, Perovskite Oxide Based Catalytic Materials and Their Auto-Exhaust Application. Appl. Catal. B Environ. 2001, 33, 165.

(34) Krogstad, J. A.; Lepple, M.; Gao, Y.; Lipkin, D. M.; Levi, C. G. Effect of Yttria 
Content on the Zirconia Unit Cell Parameters. J. Am. Ceram. Soc. 2011, 94, 4548.

(35) Kingsbury, B.; Stewart, J.; Douglas, R. Advanced Ceramic Substrate with Ordered and Designed Micro-Structure for Applications in Automotive Catalysis. SAE Tech. Pap. 2014, 2014-01-2805.

(36) Sadd, M. H. Elasticity Theory, Applications and Numerics; Academic Press:

Burlington, MA, 2009.

(37) Yuan, C. C.; Xi, X. K. On the Correlation of Young's Modulus and the Fracture Strength of Metallic Glasses. J. Appl. Phys. 2011, 109, 033515.

(38) Lawn, B. Fracture of Brittle Solids. Cambridge University Press: Cambridge, U.K., 1993.

(39) De Wit, P.; Van Daalen, F. S.; Benes, N. E. The Effect of the Production Method on the Mechanical Strength of an Alumina Porous Hollow Fiber. J. Eur. Ceram. Soc. 2017, 37,3453 .

(40) Minh, N. Q. Ceramic Fuel Cells. J. Am. Ceram. Soc. 1993, 76, 563.

(41) Milberg, M. E.; Blair, H. D. Thermal Expansion of Cordierite. J. Am. Ceram. Soc. Ceram. Soc. 1975, 60, 372.

(42) Lu, J.; Hng, H. H.; Song, X.; Zhang, T.; Ma, J. Cosintering of a Bimodal Pore Distribution Layered Structure: Constitutive Models and Experiments. J. Am. Ceram. Soc. 2010, 94, 1528.

(43) He, M. Y.; Evans, A. G.; Hutchinson, J. W. Effects of Morphology on the Decohesion of Compressed Thin Films. Mater. Sci. Eng. A. 1998, 245, 168. 
(44) González, C.; LLorca, J. Multiscale Modeling of Fracture in Fiber-Reinforced

Composites. Acta Mater. 2006, 54, 4171. 
Abstract graphic

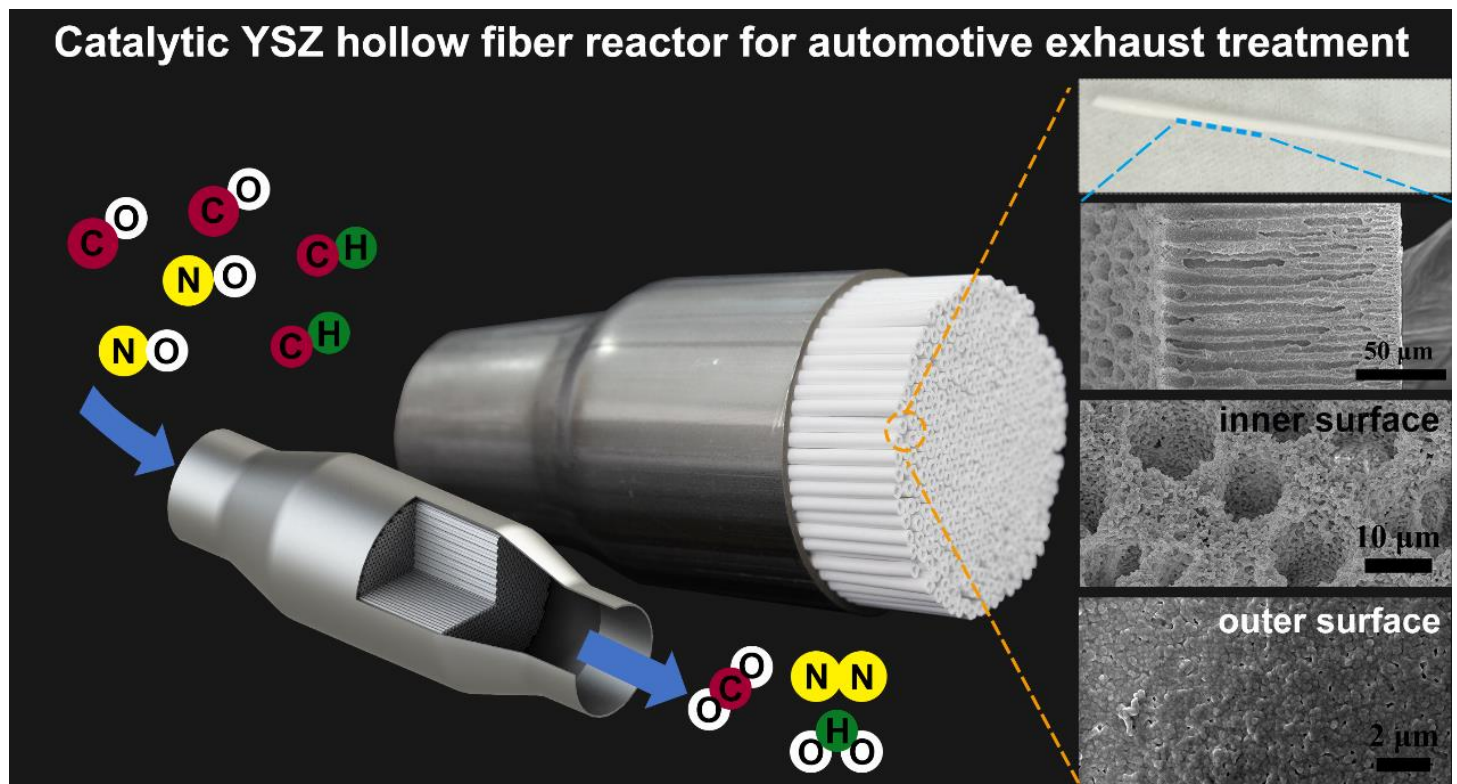

